\title{
Hubungan Kualitas Kehidupan Kerja Terhadap Motivasi Kerja Karyawan Di Puskesmas Paya Bakong Aceh Utara
}

\author{
Nur Hasmalawati \\ Program Studi Psikologi, Fakultas Psikologi, Universitas Muhammadiyah Aceh, Banda Aceh, Indonesia \\ E-mail: nurhasmalawati@gmail.com \\ Winda Putri Diah Restya \\ Program Studi Psikologi, Fakultas Psikologi, Universitas Muhammadiyah Aceh, Banda Aceh, Indonesia \\ E-mail: windaputridyahrestya @gmail.com
}

\begin{abstract}
Abstrak
Penelitin ini bertujuan untuk mengetahui pengaruh kualitas kehidupan kerja atau Quality of Work Life (QWL) terhadap motivasi kerja karyawan di Puskesmas Paya Bakong Aceh Utara. Penelitian ini merupakan penelitian deskripstif yaitu penelitian yang menyajikan gambaran lengkap mengenai suatu fenomena atau kenyataan sosial, dengan jalan mendeskripsikan sejumlah variabel yang berkenaan dengan masalah dan unit yang diteliti antara fenomena yang diteliti. Instrumen yang digunakan berbentuk skala.Populasi penelitian adalah karyawan Puskesmas Paya Bakong Aceh Utara yang berjumlah 117 orang dan diambil sampel sebanyak 54 karyawan dengan teknik simple random sampling. Teknik analisis data menggunakan analisis regresi sederhana. Hasil penelitian menunjukkan ada pengaruh kualitas kehidupan kerja terhadap motivasi kerja karyawan, artinya hipotesis yang penulis ajukan diterima. Pengaruh kualitas kehidupan kerja terhadap motivasi kerja sebesar 42,3\% dengan nilai F 38,199 dan nilai p 0,000.
\end{abstract}

Kata Kunci: Kualitas Kehidupan Kerja, Motivasi Kerja

\begin{abstract}
The aim of this research is to know the relation of quality of work life or Quality of Life (QWL) to work motivation of employees at Puskesmas Paya Bakong North Aceh. This research is descriptive research which presents complete picture about a phenomenon or social phenomenon, by way of describing variable value relating to problem and unit under study among phenomena under study. The instrument used in the scale. The research population is employees of Puskesmas Paya Bakong North Aceh which requires 117 people and taken the sample of 54 employees with simple random sampling technique. Data analysis techniques used simple regression analysis. The results showed there is influence of quality of work life to work motivation of employees, said the hypothesis that the authors submit accepted. The influence of quality of life to work motivation is $42,3 \%$ with $\mathrm{F}$ value 38,199 and $\mathrm{p}$ value 0.000 .
\end{abstract}

Keywords: Quality of Work Life, Work Motivation

Motivasi berarti suatu kondisi yang mendorong atau menjadi sebab seseorang melakukan suatu perbuatan atau kegiatan yang berlangsung secara sadar (Bangun, 2012:312). Sedangkan menurut Mathis dan Jackson (dalam Bangun, 2012:312) mengatakan motivasi merupakan hasrat didalam diri seseorang yang menyebabkan orang tersebut melakukan suatu tindakan untuk mencapai suatu tujuan. Uno (2012:71) mengatakan motivasi kerja merupakan salah satu faktor yang turut menentukan kinerja seseorang. Besar atau kecilnya pengaruh motivasi pada kinerja seseorang tergantung pada seberapa banyak intensitas motivasi yang diberikan.

Nitisemito (2010:26) mengemukakan bahwa motivasi kerja adalah usaha atau kegiatan dari pimpinan untuk dapat menimbulkan dan meningkatkan semangat dan kegairahan kerja dari para pekerja-pekerja atau karyawan-karyawannya. Sedangkan Gibson, dkk dalam
Kadarisman (2012:275) mengemukakan bahwa motivasi adalah teori yang menguraikan tentang kekuatankekuatan yang ada dalam diri karyawan yang memulai serta mengarahkan perilaku. Stokes dalam Kadarisman (2012:278) mengatakan bahwa motivasi kerja adalah sebagai pendorong bagi seseorang untuk melakukan pekerjaannya dengan lebih baik dan juga merupakan faktor yang membuat perbedaan antara sukses dan gagalnya dalam banyak hal dan merupakan tenaga emosional yang sangat penting untuk sesuatu pekerjaan baru.

Menurut Sedarmayanti (2009), kurangnya motivasi kerja dapat mempengaruhi kualitas kerja seseorang dan kualitas kerja juga berkurang, maka kepuasan orang yang menerima jasa juga akan berkurang. Oleh sebab itu, untuk meningkatkan kualitas kehidupan kerja dari tenaga kesehatan, sebaiknya pemberian motivasi kerja juga diperhatikan, misalnya pemberian insentif 
yang memuaskan. Salah satu upaya untuk meningkatkan motivasi kerja karyawan adalah dengan memperhatikan kebutuhan individualnya selama dia bekerja untuk meningkatkan kinerja dan produktivitas kerja agar tercapainya tujuan instansi tersebut.

Tekanan persaingan dalam dunia bisnis menuntut perusahaan untuk memikirkan cara perusahaan beradaptasi dengan lingkungan yang senantiasa berubah. Perusahaan harus sangat memperhatikan perubahan dunia bisnis jika mereka ingin mempertahankan tenaga kerja yang produktif. Dalam hal ini, Manajemen Sumber Daya Manusia (MSDM) mempunyai tanggung jawab yang besar untuk mengatur setiap karyawannya agar termotivasi dalam bekerja dan produktif bagi suatu perusahaan dan juga berperan dalam membangun perilaku yang kondusif bagi karyawan agar mendapatkan hasil yang terbaik. MSDM merupakan ilmu dan seni yang mengatur hubungan dan peranan tenaga kerja agar efektif dan efisien dalam membantu terwujudnya tujuan perusahaan, karyawan dan masyarakat (Hasibuan, 2008:10).

Adapun untuk mewujudkan lingkungan kerja dan iklim kerja yang kondusif, perusahaan dapat mengelola dan menyediakan sarana serta prasarana yang diharapkan bisa mendorong karyawan selalu berinovasi dan berkreasi, seperti membuat sistem yang fair, struktur organisasi yang fleksibel dengan pembagian tugas, wewenang beserta tanggung jawab yang jelas dan manusiawi, memperhatikan kemampuan karyawan dan usahanya dalam mencapai tujuan karirnya (Husnawati, 2006:2). Oleh sebab itu, terciptanya kualitas kehidupan kerja yang bagus, maka akan memotivasi karyawan untuk mengembangkan karirnya dalam suatu organisasi.

Menurut Lewis, dkk (dalam Arifin, 2012:12) kualitas kehidupan kerja merupakan masalah utama yang patut mendapat perhatian organisasi. Kualitas kehidupan kerja juga menumbuhkan keinginan para karyawan untuk tetap tinggal dan bertahan di dalam organisasi. Sedangkan Obsorn, dkk (dalam Yusuf, 2010:2) mendefinisikan kualitas kehidupan kerja sebagai quality of work life is overall quality of human experiences in the workplace, yang artinya kualitas kehidupan kerja merupakan keseluruhan kualitas dari pengalaman manusia dalam tempat kerja. Cascio (2010:24) menyatakan bahwa "quality of work life in terms of employees perceptions of their physical and mental wel-being of work" diartikan bahwa kualitas kehidupan kerja adalah persepsi karyawan akan kesejahteraan mental dan fisik mereka di tempat kerja.

Menurut Walton (dalam Rose, dkk, 2006), terdapat delapan komponen utama yang berkaitan dengan kualitas kehidupan kerja, yaitu (1) kompensasi yang cukup dan adil, (2) kondisi pekerjaan yang sehat dan aman, (3) kesempatan untuk menggunakan dan mengembangkan kapasitas yang dimiliki oleh karyawan, (4) kesempatan untuk pertumbuhan berkelanjutan, (5) integrasi sosial dalam organisasi, (6) hak-hak karyawan, (7) keseimbangan antara kehidupan kerja dan kehidupan diluar pekerjaan dan (8) relevansi sosial dalam kehidupan kerja.

Salah satu dampak kualitas kehidupan kerja yang buruk adalah timbulnya stres di tempat kerja. Stres kerja merupakan istilah umum yang menunjuk pada tekanan dan masalah yang dialami oleh setiap orang dalam kehidupan kerjanya. Konsep stres kerja mengandung dua makna yaitu positif dan negatif. Jika orang dapat mengatur atau mengelola stres dengan baik maka secara psikologis akan menumbuhkan semangat dan motivasi untuk bekerja. Sebaliknya jika stres terlalu berlebihan akan menyebabkan terganggunya kesehatan baik secara fisik maupun non-fisik (Ekowati, 2009).

Menurut Rivai \& Sagala (2010), karyawan yang mengalami stres pekerjaan dan kualitas kehidupan kerjanya rendah mempunyai sikap ketidakpuasan, sikap apatis, kebingungan terhadap peran dan kewajiban, tidak mempercayai orang lain, bimbang dalam mengambil keputusan, mudah marah dan selalu menunda pekerjaan. Jika hal ini terjadi dan tidak segera ditanggulangi, maka kinerja dan produktivitas karyawan akan menurun yang menyebabkan karyawan tidak puas dengan pekerjaannya. Oleh sebab itu muncul keinginan atau kecenderungan untuk keluar atau meninggalkan pekerjaan sehingga tidak tercapainya tujuan dari perusahaan tersebut.

Berdasarkan uraian di atas, dapat dilihat bahwa ada pengaruh yang sangat penting antara kualitas kehidupan kerja dengan motivasi kerja karyawan terhadap kinerja dan produktivitas tenaga kerja, oleh sebab itu peneliti tertarik ingin meneliti tentang "Pengaruh Kualitas Kehidupan Kerja atau Quality of Work Life terhadap Motivasi Kerja Karyawan di Puskesmas Paya Bakong, Kabupaten Aceh Utara.

\section{METODE}

Penelitian ini merupakan penelitian deskripstif yaitu penelitian yang menyajikan gambaran lengkap mengenai suatu fenomena atau kenyataan sosial, dengan jalan mendeskripsikan sejumlah variabel yang berkenaan dengan masalah dan unit yang diteliti antara fenomena yang diteliti. Populasi dalam penelitian ini berjumlah 117 orang. Sampel yang diambil sebanyak 54 orang dengan simple random sampling. Artinya pengambilan anggota sampel dari populasi dilakukan secara acak tanpa memperhatikan strata yang ada dalam populasi tersebut. Hasil penelitian kemudian dianalisis menggunakan analisis statistik regresi linear sederhana dengan menggunakan bantuan fasilitas komputer yaitu program 
SPSS (Statistical Product and Service Solution) 16.0 for Windows.

\section{HASIL DAN PEMBAHASAN}

Peneliti melihat fenomena di lapangan bahwa kebanyakan karyawan kurang antusias dalam bekerja karena merasa tidak nyaman dan kurang diperhatikan kebutuhannya ketika bekerja. Hal ini dapat dilihat dari kurangnya unit komputer yang disediakan, padahal karyawan membutuhkannya untuk memasukkan data. Karyawan juga mengatakan bahwa lingkungan kerja kurang nyaman dan kondusif, organisasi kurang memperhatikan kebersihan, kamar mandi dan mushalla kurang diperhatikan, sehingga karyawan mengalami kesulitan dalam melakukan ibadah. Hal itulah yang membuat karyawan kurang termotivasi dalam bekerja. Sumber daya manusia merupakan faktor yang sangat berharga. Oleh sebab itu, perusahaan bertanggung jawab untuk memelihara kualitas kehidupan kerja atau disebut juga dan membina tenaga kerja agar bersedia memberikan sumbangannya secara optimal untuk mencapai tujuan perusahaan (Pruijt dalam Husnawati, 2006).

Berikut peneliti menjabarkan hasil analisis yang disajikan di dalam tabel di bawah ini:

Tabel 1: Hasil Analisis Uji Korelasi

\begin{tabular}{ccc}
\hline Variabel & $\begin{array}{c}\text { Pearson } \\
\text { Correlation }\end{array}$ & Sig \\
\hline $\begin{array}{c}\text { Kualitas Kehidupan } \\
\text { Kerja \& Motivasi } \\
\text { Kerja }\end{array}$ & .651 & .000 \\
\hline
\end{tabular}

Berdasarkan tabel di atas, dapat dilihat bahwa kualitas kehidupan kerja memiliki hubungan positif yang signifikan dengan motivasi kerja. Hal ini ditunjukkan dengan nilai koefisien korelasi sebesar 0,651, nilai $\mathrm{p}$ $0,000<0$, 05. Artinya jika kualitas kehidupan kerja semakin tinggi, maka motivasi kerja juga semakin tinggi. Sebaliknya, jika kualitas kehidupan kerja rendah, maka motivasi kerja yang dimiliki juga rendah.

Tabel 2: Hasil Analisis Uji Regresi

\begin{tabular}{cccc}
\hline Variabel & F & $\mathbf{R}^{2}$ & Sig \\
\hline $\begin{array}{c}\text { Kualitas } \\
\text { Kehidupan Kerja \& } \\
\text { Motivasi Kerja }\end{array}$ & 38.199 & .423 & .000 \\
\hline
\end{tabular}

Berdasarkan tabel di atas, hasil analisis menunjukkan bahwa kualitas kehidupan kerja berpengaruh terhadap motivasi kerja karyawan. Hal ini dilihat dari nilai $\mathrm{R}$ Square 0,423 dengan nilai F 38,199 dan nilai sig 0,000 yang artinya kualitas kehidupan kerja sebagai variabel bebas mempengaruhi variabel terikat yaitu motivasi kerja sebesar 42,3\%, sedangkan sisanya 57,7 \% dipengaruhi oleh variabel lain seperti gaya kepemimpinan dan kepuasan kerja.

\section{DISKUSI}

Hasil penelitian yang telah dilakukan menunjukkan adanya pengaruh kualitas kehidupan kerja terhadap motivasi kerja yang artinya hipotesis yang diajukan diterima. Arifin (2012:13) yang berpendapat bahwa kualitas kehidupan kerja merumuskan setiap proses kebijakan yang diputuskan oleh perusahaan merupakan sebuah respon atas apa yang menjadi keinginan dan harapan karyawan mereka, hal itu diwujudkan dengan berbagi persoalan dan menyatukan pandangan mereka (perusahaan dan karyawan) ke dalam tujuan yang sama yaitu peningkatan kinerja karyawan dan perusahaan.

Pendapat Arifin (2012:13) berkaitan dengan teori kualitas kehidupan kerja yang dikemukakan oleh Wayne (dalam Yusuf (2010:2) yang menyatakan bahwa pimpinan perusahaan perlu menyikapi dengan sebaikbaiknya makna dari konsep Quality of Work Life dengan tujuan agar hubungan antara pihak manajemen dengan karyawan dapat berjalan dengan baik yang bermuara peningkatan kinerja. Adanya kualitas kehidupan kerja juga menumbuhkan keinginan para karyawan untuk tetap tinggal dan bertahan di dalam organisasi.

Banyak penelitian yang telah dilakukan dan hasilnya menunjukkan bahwa terdapat hubungan positif yang signifikan antara QWL dengan beberapa variabel lain dalam organisasi, seperti motivasi kerja dan kepuasan karyawan (Fitriadi, 2012). Penelitian yang dilakukan oleh Samtica (2011) tentang hubungan komponen QWL dengan motivasi kerja juga menunjukkan hasil yang signifikan. Sama halnya dengan Mochtar (2012) yang melakukan penelitian tentang QWL dengan kinerja, hasil penelitian menunjukkan bahwa adanya hubungan positif yang signifikan.

Kualitas kehidupan karyawan sangat perlu diperhatikan, karena dengan memperhatikan kualitas kehidupan kerja, maka akan memotivasi karyawan untuk mengembangkan karirnya dalam suatu organisasi. Jika atasan belum sepenuhnya memperhatikan kebutuhan dan keinginan karyawan, maka motivasi kerja karyawan rendah dan tidak memberikan kinerja yang optimal dalam meningkatkan keuntungan bagi perusahaan.

Puskesmas Paya Bakong belum menyediakan sarana dan prasarana yang diinginkan dan dibutuhkan karyawan. Kondisi tempat dan lingkungan kerja yang disediakan belum kondusif dan mendukung, seperti tempat ibadah dan kamar mandi yang disediakan tidak terjaga kebersihannya, fasilitas komputer yang disediakan belum memadai dan kepercayaan serta citra Puskesmas dimata masyarakat masih rendah. Oleh sebab itu, Kepala Puskesmas harus sangat 
memperhatikan kondisi tempat dan lingkungan kerja supaya lebih kondusif, sehingga karyawan akan termotivasi dan semangat dalam bekerja untuk mewujudkan tujuan Puskesmas kedepannya.

\section{Kelemahan Penelitian}

Penelitian ini memiliki beberapa hal yang menjadi kelemahan dan keetrbatasan, yaitu:

- Pengambilan data dilapangan dengan menggunakan angket. Penyebaran angket dilakukan dengan cara menyebar langsung dan didampingi oleh peneliti dan sebagian ada yang tidak didampingi, sehingga peneliti tidak dapat mengantisipasi hal yang mungkin terjadi seperti responden yang kurang memahami maksud dari pernyataan yang diberikan.

- Kelemahan yang lain adalah sebagian kebenaran jawaban dari responden bukan keadaan diri responden yang sebenarnya karena mengisi angket asal-asalan dan sebagian responden yang takut dinilai tidak baik oleh peneliti.

\section{PENUTUP}

\section{Simpulan}

Berdasarkan pembahasan yang telah diuraikan sebelumnya, maka dapat disimpulkan bahwa adanya pengaruh kualitas kehidupan kerja terhadap motivasi kerja karyawan. Untuk dapat meningkatkan motivasi kerja karyawan maka harus terciptanya suasana kerja yang baik supaya karyawan dapat merasakan adanya keterlibatan dalam organisasi atau perusahaan. Setiap organisasi berperan penting dalam menciptakan kinerja yang terbaik untuk mencapai tujuan yang diinginkan, karena untuk mencapai tujuannya, perusahaan hendaknya menyadari bahwa membutuhkan bantuan, loyalitas dan partisipasi dari karyawan atau bawahannya dengan cara memperhatikan kualitas kehidupan kerja karyawan selama dia bekerja.

\section{Saran}

Atasan sebaiknya lebih memperhatikan dan menyediakan sarana dan prasarana dalam rangka mewujudkan lingkungan kerja dan iklim kerja yang kondusif dan diharapkan bisa mendorong karyawan selalu berinovasi dan berkreasi. Atasan juga mengadakan pelatihan-pelatihan untuk meningkatkan pengetahuan dan wawasan karyawan secara bergantian dan melakukan evaluasi kepada karyawan yang sudah mendapatkan pelatihan. Karena dengan terciptanya kualitas kehidupan kerja yang bagus, maka akan memotivasi karyawan untuk mengembangkan karirnya dalam suatu organisasi dan mewujudkan tujuan organisasi tersebut.

\section{DAFTAR PUSTAKA}

Arifin, N. (2012). Analisis Kualitas Kehidupan Kerja, Kinerja dan Kepuasan Kerja Pada CV. Duta Senenan Jepara. Journal Economia. Volume 8 No. 1. Hal 11-21. Jepara: STIENU Jepara.

Bangun, W. (2012). Manajemen Sumber Daya Manusia. Jakarta: Erlangga.

Cascio, W, F. (2010). Managing Human Resources. Productivity, Quality of Work Life, profits. Eight Edition, New York: McGraw-Hill/Irwin.

Ekowati, T. (2009). Quality of Work Life: Upaya Antisipasi Stres di Tempat Kerja. Jurnal. Published in www.um-pwr.ac.id.

Fitriadi, B. Y. (2012). Analisis Pengaruh Kualitas Kehidupan Kerja terhadap Motivasi Kerja dan Kinerja Karyawan PT. Bank Muamalat Indonesia Jember. Skripsi. Fakultas Ekonomi Universitas Jember.

Hasibuan, M. (2008). Manajemen Sumber Daya Manusia. Edisi Revisi. Jakarta: Bumi Aksara.

Husnawati, A. (2006). Analisis Pengaruh Kualitas Kehidupan Kerja Terhadap Kinerja Karyawan Dengan Komitmen dan Kepuasan Kerja Sebagai Intervening Variabel. Studi Pada Perum Pegadaian Kanwil VI Semarang. Tesis. Program Studi Magister Manajemen. Program Pasca Sarjana, Universitas Diponegoro, Semarang.

Kadarisman, M. (2012). Manajemen Pengembangan Sumber Daya Manusia. Jakarta: PT. Raja Grafindo Persada.

Mochtar, H. (2012). Hubungan Komponen Quality of Work Life dengan Kinerja Bidan. Tesis. Fakultas Kesehatan Masyarakat. Universitas Indonesia.

Nitisemito, A, S. (2010). Manajemen Personalia: Manajemen Sumber Daya Manusia. Jakarta: Ghalia Indonesia.

Rivai, V \& Sagala, E. J. (2010). Manajemen Sumber Daya Manusia untuk Perusahaan, dari Teori ke Praktik. Edisi Kedua. Jakarta: PT. Raja Grafindo Persada.

Rose, R, C., Beh, L., Uli, J., \& Idris. (2006). Quality of Work Life: Implication of Career Dimensions. Journal of Social Sciences. 2 (2): 61-67.

Samtica, S. (2011). Hubungan Komponen Kualitas Kehidupan Kerja atau Quality of Work Life dengan Motivasi Kerja Perawat Pelaksana di RS Haji Jakarta. Skripsi. Fakultas Kesehatan Masyarakat. Universitas Indonesia. 
Sedarmayanti. (2009). Manajemen Sumber Daya Manusia. Bandung: Reformasi Birokrasi.

Uno, H. B. (2012). Teori Motivasi dan Pengukurannya. Jakarta: PT. Bumi Aksara.

Yusuf, T. (2010). Pengaruh Kualitas Kehidupan Kerja, Komitmen Kerja dan Motivasi Terhadap Kepuasan Kerja Karyawan (Studi Kasus Karyawan PDAM Makassar). Jurnal Ekonomi. Balikpapan: Universitas Balikpapan. 